\title{
Surface Wave Modeling in Coastal Waters
}

\author{
Miao Tian* \\ Coastal Engineer, INTERA Incorporated, USA
}

Submission: April 24, 2017; Published: June 28, 2017

*Corresponding author: Miao Tian, Coastal Engineer, INTERA Incorporated, Gainesville, Florida 32606,USA, Email: mtian@intera.com

\section{Introduction}

Coastal surface waves are critical in studying the complex marine systems and have large-scale implications on coastal engineering applications. Waves can be observed in all sizes and forms in water open to the atmosphere, depending on magnitude of the forces acting on the water [1]. Therefore, different categories of surface waves exist. One way to characterize them is based on their distinct temporal scales, associated with various generating mechanisms. For example, wind waves have a typical period of 16 seconds or smaller, which are generated locally when wind blowing over the water surface. Swells, with a period of 12-20 seconds, are waves that have traveled away from the area in which they were formed, either from a distant storm or combination of waves from different wind systems. Infragravity waves (also known as surf beat, see [1]) are long, bound waves whose period ranges from 20 seconds to the order of minutes, can be forced by either nonlinear difference interactions between short waves [2-5] or short-wavesinduced radiation stresses [6,7]. Tsunami waves, in spite of its non-periodic wave form, appear to be much longer with an effective duration of 15 minutes to 1 hour; and can be induced by earthquakes or landslides in the ocean [8]. There are other types of coastal wave motion, e.g., boat wakes induced by ship motions $[9,10]$, acoustic-gravity waves [11], storm surges due to hurricanes, capillary waves associated with surface tension, continental coastal shelfwaves produced by earth Coriolis force, (for details see [12]). In this review, we confine ourselves to surface waves in the near shore.

Usual approaches to simulate surface wave propagation fall into two categories: wave-resolving and phase-resolving models. Wave resolving models involve using Boussinesq type wave equations with modified nonlinearity and dispersion characteristics for the simulation of wave propagation, especially in shallow water regions [13-15]. A more straight forward method is to solve the Navier-Stokes equations directly with proper free surface tracking techniques, such as the volume- of-fluid (VOF) method [16] and the level-set method [17]. They have been widely applied to wave shoaling and breaking simulations in the surf zone [18-20]. One disadvantage of these methods is that they are computationally expensive therefore cannot be utilized for large-scale simulation. Furthermore, because the free surface normally crosses the computational cell arbitrarily, the pressure boundary condition is difficult to be precisely exerted on the free surface. One approach to simplify the above-mentioned method is to consider the free surface elevation as a single value function of the horizontal coordinates. Under this assumption, the free surface always stays at the upper computational boundary, therefore, can be computed by using the free surface boundary conditions. This treatment leads to a family of non-hydrostatic wave models. Different approaches to discretize the governing equations have been developed, such as finite difference method [21,22], finite element method [23] and finite volume method $[24,25]$. Another non-trivial problem in non-hydrostatic modeling is to simulate breaking waves in the surf zone and wave run-up in the swash region, because the numerical scheme must treat shock propagation adequately [22]. Shock-capturing schemes based on a Godunov - type approach are suitable for breaking wave simulations because they can deal with discontinuous flow. This approach has been applied to simulate breaking waves in the surf zone [24]. A state-of-the-art nonhydrostatic wave model, NHWAVE [26], also implements this approach to its numerical scheme for simulations of tsunami induced by submarine landslides [20], infragravity waves over fringing reefs [27], and solitary wave breaking over a sloping bed [8].

An alternative approach to simulate wave shoaling, refraction, diffraction, and breaking is developed by the use of phase-resolving models. They are usually more computationallyefficient and more suitable for large-scale wave-field simulation as compared with wave-resolving models, because they solve the governing equations in spectra domain. In deep water (e.g., (kh)2 
$0: 5$, where $\mathrm{k}$ represents the characteristic wave number and $\mathrm{h}$ is the local water depth), the WAM-class of models (e.g., SWAN, Booij et al.[28] WAVEWATCH III, Tolman [29]), which numerically implements the wave action equation, are able to capture bulk second order statistics (wave energy, significant wave height) relatively well. Nearshore wave transformation, however, is associated with wave over varying bathymetry therefore needs different treatment. This problem has been generally solved by the use of the Mild-Slope approximation, which assumes the depth change within one wavelength is small, i.e., $\tilde{N} h=k h O(1)$. In the framework of the Mild-Slope approximation, waves are assumed to travel though a flat bottom locally, but have large variations across long distance. The pioneering formulation of Berkhoff [30] has been followed by extensions [31-34]. These linear wave models are insufficient because near shore waves exhibit strongly-nonlinear features. Because the nonlinear resonance condition for a single triad can be satisfied exactly in shallow water, triad interaction dominates nearshore wavewave interaction. Unidirectional triad-interaction wave models have been developed [2,3] and extended to a directional version $[35,36]$. Enormous efforts have been made to include various physical processes into phase-resolving models, such as white capping, bottom friction, wave breaking [5], wave-current interaction $[37,38]$, and so on.

In general, two approaches (wave-resolving and phaseresolving) have been implemented to cope with surface wave modeling in coastal waters. Although wave-resolving simulations usually require large computing resources, they conduct direct numerical simulation to the governing equations therefore are able to accurately simulate complicated wave phenomena. Recent development of non-hydrostatic approach with shock-capturing scheme enables the model to simulate wave breaking and run-ups in very shallow water, e.g., swash zone $[22,26]$. Phase-resolving models, on the other hand, are naturally suitable to simulate large-scale wave propagation due to its computational efficiency. Both deep-water and near-shore wave models have been developed for directional wave spectrum evolution. Physical effects such as windinput, white-capping, and bottom friction have improved the model performance. Future effort will focus on combining wave-resolving and phaseresolving models to integrated wave modeling systems [39-41].

\section{References}

1. Dean RG, Dalrymple RA (1991) Water Wave Mechanics for Engineers and Scientists, Ad-vanced Series on Ocean Engineering. World Scientific 2(174): 176.

2. Agnon Y, Sheremet A, Gonsalves J, Stiassnie M (1993) A unidirectional model for shoaling gravity waves. Coastal Engng 20: 29-58.

3. Agnon Y, Sheremet A (1997) Stochastic nonlinear shoaling of directional spectra. J Fluid Mech 345: 79-99.

4. Herbers T, Burton M (1997) Nonlinear shoaling of directionally spread waves on a beach. J Geophy Res 102(C9): 21101-21114.
5. Kaihatu J, Kirby J (1995) Nonlinear transformation of waves in finite water depth. Phys Fluids 7(8): 1903-1914.

6. Longuet-Higgins M, Stewart R (1962) Radiation stress and mass transport in gravity waves with application to surf beats. J Fluid Mech 13(4): 481-504.

7. Mei CC, Stiassnie M, Yue DP (2005) Theory and applications of ocean surface waves. Adv Series on Ocean Eng Expanded Edition World Scientific.

8. Tian M, Sheremet A, Kaihatu JM, Ma GF (2015) On the Shoaling of Solitary Waves in the Presence of Short Random Waves, Journal of Physical Oceanography 45(3): 792-806.

9. Sheremet, Gravois U, Tian M, Blankenship TK (2011) Boat-Wake Observations at Jensen Beach, Florida. Coastal Engineering Practice 1034-1042.

10. Sheremet A, Gravois U, Tian M (2012) Boat-wake statistics at Jensen Beach, Florida (2012) Journal of Waterway, Port, Coastal, and Ocean Engineering 139(4): 286-294.

11. Tian M, Kadri U (2016) Wavemaker theories for acoustic-gravity waves over a finite depth. Journal of Engineering Mathematics p. 1-11.

12. Mellor GL (1996) Introduction to physical oceanography. American Institute of Physics.

13. Madsen PA, Sørensen OR (1992) A new form of the Boussinesq equations with improved linear dispersion characteristics. Part A slowly-varying bathymetry. Coastal Eng 18: 183-204.

14. Nwogu $O$ (1993) Alternative form of Boussinesq equations for nearshore wave propagation. J Waterway Port Coastal Ocean Eng 119(6): 618-638.

15. Wei G, Kirby JT, Grilli ST, Subramanya R (1995) A fully nonlinear Boussinesq model for surface waves. Part 1. Highly nonlinear unsteady waves. J Fluid Mech 294(32): 71-92.

16. Hirt CW, Nichols BD (1981) Volume of fluid (VOF) method for the dynamics of free bound-aries. J Comput Phys 39: 201-225.

17. Osher A, Sethian JA (1988) Fronts propagating with curvaturedependent speed: algorithms based on Hamilton-Jacobi formulations. J Comput Phys 79: 12-49.

18. Lin P, Liu PLF (1998) A numerical study of breaking waves in the surf zone. J Fluid Mech 359: 239-264.

19. Shi F, Kirby JT, Ma G (2010) Modeling quiescent phase transport of air bubbles induced by breaking waves. Ocean Modell 35(1): 105-117.

20. Ma G, Kirby JT, Hsu TJ, Shi F (2015) A two-layer granular landslide model for tsunami wave generation: Theory and computation. Ocean Modelling 93: 40-55.

21. Casulli V, Stelling G (1998) Numerical simulation of $3 \mathrm{~d}$ quasihydrostatic, free- surface flows. J Hydr Eng ASCE 124(7): 678-686.

22.Zijlema M, Stelling G, Smit P (2011) Swash: An operational public domain code for simulating wave fields and rapidly varied flows in coastal waters. Coast Engn 58(10): 992-1012.

23. Walters RA (2005) A semi-implicit finite element model for nonhydrostatic (dispersive) surface waves. Int J Numer Methods Fluids 49: 721-737.

24. Bradford SF (2011) Nonhydrostatic model for surf zone simulation. J Waterway Port Coastal Ocean Eng 137(4): 163-174.

25. Fringer OB, Gerritsen M, Street RL (2006) An unstructured-grid, finite-volume, nonhydro-static, parallel coastal ocean simulator. Ocean Modell 14: 139-173. 
26. Ma GF, Shi F, Kirby JT (2012) Shock-capturing non-hydrostatic model for fully dispersive sur-face wave processes. Ocean Model 43-44: 22 35 .

27. Ma G, Su SF, Liu S, Chu JC (2014) Numerical simulation of infragravity waves in fringing reefs using a shock-capturing non-hydrostatic model, Ocean Engineering 85: 54-64.

28. Booij N, Ris RC, Holthuijsen LH (1999) A third-generation wave model for coastal regions: Model description and validation. J Geophys Res 104(4): 7649-7666.

29. Tolman HL (1991) A third generation model for wind on slowly varying, unsteady and inhomo-geneous depth and currents. J Phys Oceanogr 21: 766-781.

30. Berkhoff J (1972) Computational of combined refraction-diffraction Proc of the $13^{\text {th }}$ Int Conf on Coastal Engineering ASCE, pp. 471-490.

31. Chamberlain PG, Porter D (1995) The modified mild slope equation. J Fluid Mech 291: 393-407.

32. Kirby J (1986) A general wave equation for waves over rippled beds. J Fluid Mech 162: 171-186.

33. Massel S (1993) Extended refraction-diffraction equation for surface waves. Coastal Eng 19: 97-126.
34. Porter D, Staziker DJ (1995) Extension of the mild-slope equation. J Fluid Mech 300: 367-382.

35. Davis JR, Sheremet A, Tian M, Saxena S (2014) A numerical implementation of a nonlinear mild slope model for shoaling directional waves, Journal of Marine Science and Engineering 2(1): 140-158.

36. Sheremet, Davis JR, Tian M, Hanson JL, Hathaway KK (2016) TRIADS: A phase-resolving model for nonlinear shoaling of directional wave spectra. Ocean Modelling 99: 60-74.

37. Tian M, Cottrell W, Sheremet A, Smith J (2012) The quasi-stream function formalism. Proceedings of 33rd Conference on Coastal Engineering, Santander, Spain, 33.

38. ZF Dong, JT Kirby (2012) Theoretical and numerical study of wavecurrent interaction in strongly-sheared flows. Coastal Engineering, Santander Proceedings, Spain, 33.

39. Bradford SF (2005) Godunov-based model for nonhydrostatic wave dynamics. J Waterway Port Coastal Ocean Eng 131(5): 226-238.

40. Dean RG, Dalrymple A (2002) Coastal processes with engineering applications. Cambridge University Press, UK.

41. Ma G, Shi F, Kirby JT (2011) A polydisperse two-fluid model for surf zone bubble simulation. J Geophys Res 116.

\section{Your next submission with Juniper Publishers will reach you the below assets}

This work is licensed under Creativ

DOI: 10.19080/OFOAJ.2017.03.555609

- Quality Editorial service

- Swift Peer Review

- Reprints availability

- E-prints Service

- Manuscript Podcast for convenient understanding

- Global attainment for your research

- Manuscript accessibility in different formats

( Pdf, E-pub, Full Text, Audio)

- Unceasing customer service

Track the below URL for one-step submission https://juniperpublishers.com/online-submission.php 